\title{
Research on System Design of Performance Evaluation for Public Sports Service
}

\author{
Wei Zou ${ }^{1, a}$ \\ ${ }^{1}$ Department of sports, HuaZhong Agriculture University, Wuhan 430070, China \\ a12247411@qq.com
}

Keywords: Public sports service; Performance evaluation; System design

\begin{abstract}
In a public sports service system, performance evaluation is an important component which can play the function of improving quality of public sports service and enhancing efficiency of public sports service. Following the rule of performance evaluation system design for public sports service, this paper carries out researches on design issues of this system, so as to provide references for people who focus on this topic.
\end{abstract}

\section{Introduction}

The so-called public sports service is actually the responsibility which the government should undertake in production and supply of social public sports goods and services to satisfy public sports demand. Performance evaluation for this kind of service needs to utilize scientific method, procedure and standards to evaluate the performances of public sports service provided by the government. To better promote development of public sports service utilities, it is necessary to conduct system design for public sports service performance evaluation. Accordingly, scientific evaluation can be better carried out to relevant performances achieved by the government with this system.

\section{Design Principles of Public Sports Service Performance Evaluation System}

In the design of public sports service performance evaluation system, corresponding design principles shall be followed to ensure that actual level and development trend of public sports service performances are accurately and objectively reflected. Firstly, system design shall abide by systematic principle. The reason is that this system is integrated by performance systems in multiple aspects such as degree of public service input, public service efficiency and public satisfaction. This requires the system to possess enough coverage to show systematic characteristics of public sports service performance. Secondly, system design needs to abide by operability principle, so that data of the indicator system can be easily acquired, and personnel who use the system can easily grasp and operate it. Moreover, system design shall follow the principles of combination of ability and effect and combination of internal and external evaluations. Specifically, public service quality of the unit to be examined shall be emphasized, as well as input and output of the unit to be examined, to ensure effect of system evaluation. Meanwhile, the opinions of the personnel to be evaluated and the service objects need to be heard. In this way, the comments and suggestions of internal and external personnel can be absorbed comprehensively, and public satisfaction will be further improved. Besides, system design shall follow the dynamic principle. This is because public sports service performance needs to get dynamic accumulation, it cannot show its true value in a short time [1]. Consequently, in selection of evaluation indicators, static indicators and dynamic indicators need to be combined to better predict future trend of performance development. At last, system design shall follow the guiding principle so find out the problems of public sports service and finally reach the goal of promoting public sports development. 


\section{Design Implementation of Public Sports Service Performance Evaluation System}

\subsection{System Structure Design}

From the perspective of system structure, multiple indicators contained in the public sports service performance evaluation system can be divided into four levels, which are respectively system level, sub-system level, status level and element level. Wherein, the system level can carry out comprehensive evaluation on performance conditions of the public sports service in a region on the whole. The sub-system level comprises five sub-systems, which respectively are competitive sports, school physical education, social sports, sports science and technology and sports information. They can provide orientation for classified evaluation of public sports service performance. The status level has used the international method for public service performance evaluation for reference. Each sub-system needs to be divided into input, output and effect [2]. By setting the indicator of input, the financial resources, material resources and human resources of input in various public sports services can be measured. Thus this indicator can reflect the attitude of the government towards supply of public sports services and meanwhile reflect supply capacity of the government. By setting the indicator of output, the quantity of services supported by service input can be measure, and meanwhile capacities of these services can be measured. Besides, establishment of the indicator for effect is to evaluate the final influence of the services and reflect the degree of fairness in accepting the services by vulnerable groups. In the process of specific design, to further improve the evaluation indicators, 15 experts and scholars from higher schools and Municipal Bureau of Sports are employed and consulted, and corresponding questionnaire survey is carried out [3]. Finally, the designed system comprises four sub-systems, which are respectively social sports, school physical education, competitive sports and sports science and technology, and contains 89 indicators.

3.2 Preliminary Evaluation on System Indicators

In the process of system design, evaluation on system indicators needs the analysis on degree of membership of each indicator. For this reason, the system shall be regarded as a fuzzy set, the evaluation indicators shall be regarded as elements in the set, and then analysis on degree of membership shall be conducted to each indicator. In the process of evaluation, it means that there are $\mathrm{Mn}$ experts who consider that $\mathrm{Xn}$ is important if the total number of expert choice of the Nth evaluation indicator $\mathrm{Xn}$ is $\mathrm{Mn}$, thus this indicator is possibly subordinate to the indicator system. On the contrary, if most experts think that this indicator is not so important, it can be regarded that degree of membership of this indicator is low, and the indicator will be excluded from the system. In designing the public sports service performance evaluation system, degrees of membership of 89 indicators are obtained through statistics of 15 effective questionnaire surveys conducted to the experts under the condition that the critical value for degree of membership is set as 0.4[4]. After multiple evaluation indicators with degree of membership lower than 0.4 are deleted, 57 evaluation indicators are acquired.

\subsection{In-depth Screening of System Indicators}

After the preliminary evaluation, high correlation may still exist among the evaluation indicators selected by the experts. Existence of the correlation may result in repeated use of object information, and further lead to reduction of scientificity of the evaluation result. To avoid this, further analysis needs to be carried out on correlation coefficient of system indicators so as to delete the indicators which have high relevancy with other indicators and low degree of membership. In this way, construction of the system is completed. Correlation analysis is conducted to the data of second round of survey by SPSS statistical software to obtain correlation coefficient matrix of each indicator [5]. For instance, in performance indicators of social sports, there are 4 pairs of evaluation indicators whose correlation coefficient is larger than the set critical value 0.6 in the correlation coefficient matrix, thus the four indicators need to be deleted. Finally, the evaluation indicators of the designed system and their weights are as listed in Table 1. There are four sub-systems including competitive sports, school physical education, social sports and sports science and technology. 33 specific indicators are contained. 
Table 1 Evaluation Indicators for Public Sports Service Performance of the Government and Weight of the Indicators

\begin{tabular}{|c|c|}
\hline Type of Indicator & Output \\
\hline \multirow[t]{2}{*}{$\begin{array}{l}\text { Competitive } \\
\text { Sports }(0.205)\end{array}$} & 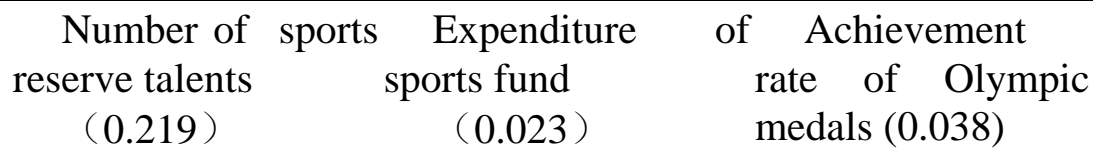 \\
\hline & 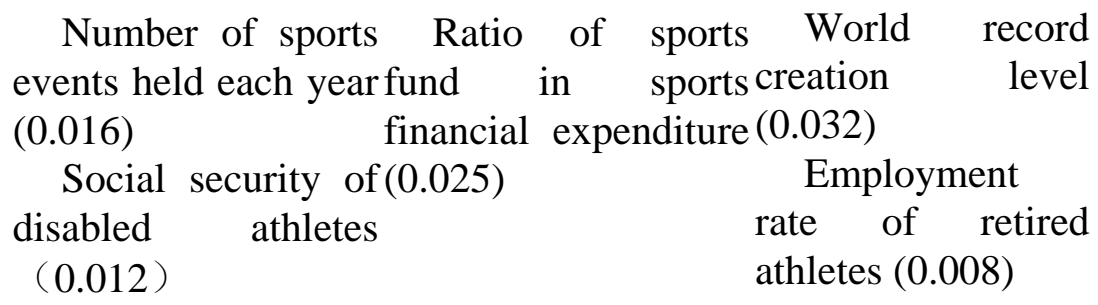 \\
\hline $\begin{array}{c}\text { School Physical } \\
\text { Education }(0.226)\end{array}$ & 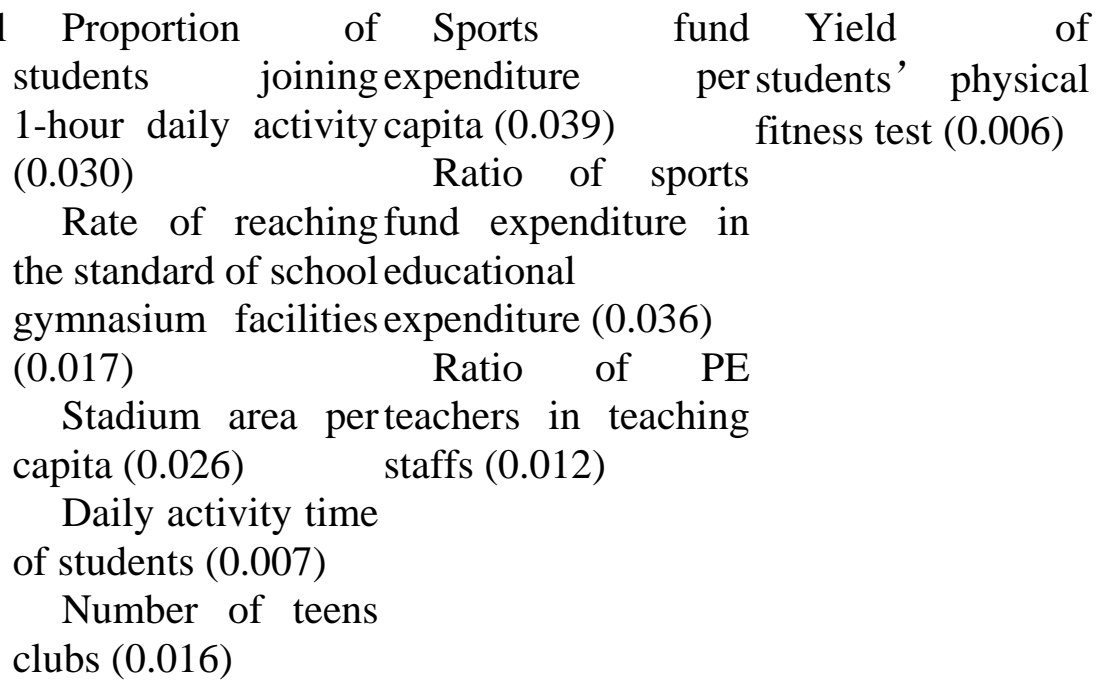 \\
\hline $\begin{array}{l}\text { Social } \\
(0.432)\end{array}$ & 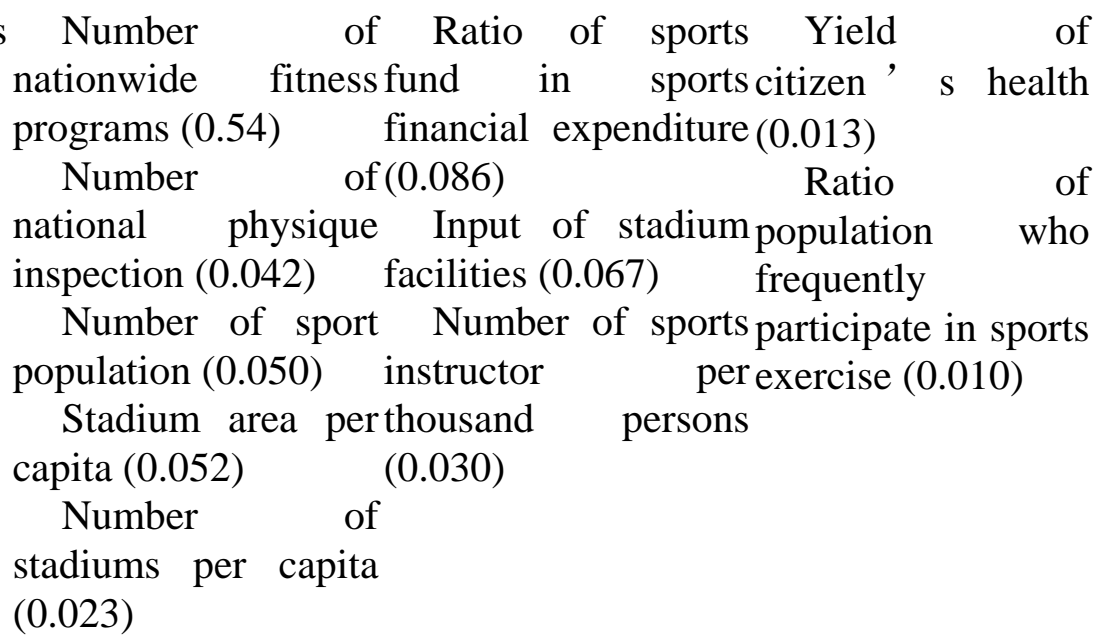 \\
\hline $\begin{array}{l}\text { Sports Science anc } \\
\text { Technology (0.136) }\end{array}$ & \begin{tabular}{lccr} 
National scientific & Expenditure & of Number & of \\
research & awards sports science & and scientific & and \\
$(0.028)$ & technology & fund technical personnel \\
Number & of $(0.021)$ & per hundred athletes \\
provincial & scientific Ratio of & sports $(0.022)$ \\
research & projects science & and Ratio of sports \\
$(0.025)$ & technology fund in patent & \\
& \multicolumn{2}{c}{ sports fund (0.023) } & authorizations and \\
& & & applications $(0.015)$
\end{tabular} \\
\hline
\end{tabular}




\subsection{Implementation of System Design}

When public sports service performance evaluation is conducted to the government by means of the designed system, calculation on comprehensive evaluation value of each system factor shall be conducted according to the weight of the element level of each sub-system. Based on that, final calculation on evaluation value of the system level can be conducted with the formula $F=\sum_{i=1}^{\mathrm{n}}\left(W_{i}^{*} V_{i}\right)$ according to the weights of these evaluation values and the system level. Wherein, $\mathrm{F}$ refers to comprehensive evaluation value, Wi refers to the weight of the ith evaluation value, Vi refers to the increment of the ith evaluation value, and $n$ refers to the number of system indicators.

\section{Conclusion}

In a word, by analyzing various factors which affect the level of public sports service, this paper designs an indicator system for public sports service performance evaluation which covers four sub-systems including competitive sports, school physical education, social sports and sports science and technology and other 33 specific indicators. With this system, comprehensive reflection for each level of public sports service performance evaluation can be achieved, so that scientific basic is provided for management of public sports service institutions. Furthermore, development of public sports service in China can be better promoted.

\section{Acknowledgements}

This work was supported by the Fundamental Research Funds for the Central Universities.

\section{References}

[1] Wang Jingbo, Zhao Shunlai, Wei Pilai et al. Evaluation Indicators System of Sports Public Services Performance of Local Government [J]. Journal of Shenyang Sport University, 2011, 02: $1-3+7$.

[2] Liu Liang. Performance Assessment of Sports Public Service Under New Public Management Perspective - Based on Investigation and Analysis on Wuhan " $1+8$ " Metropolitan Area [J]. Journal of Wuhan Institute of Physical Education, 2011, 06: 24-29.

[3] Tang Licheng, Tang Lihui, Wang Di. Evaluation Model and Strategies for the Performance of Service Management of Public Stadium and Gymnasium [J]. Journal of Beijing Sport University, 2010, 01:24-27.

[4] Song Namei, Luo Yanping, Zheng Li. The Evaluation of the Public Service Performance of PE: the Construction of Index System and Scoring Method [J]. Journal of Sports and Science, 2012, 05: 30-34.

[5] Peng Guohua, Zhang Li. Study on Evaluation System of Rural Public Sports Service Performance in Guangdong Province - Based on the Perspective of Farmer's Satisfaction [J]. Journal of Anhui Sports Science, 2015, 01: 17-20. 